\title{
Polymorphisms in the ICAM1 gene predict circulating soluble intercellular adhesion molecule-1(sICAM-1)
}

\author{
Suzette J. Bielinski ${ }^{1}$, Alex P. Reiner ${ }^{2}$, Deborah Nickerson ${ }^{3}$, Chris Carlson ${ }^{4}$, Kent R. Bailey ${ }^{5}$, \\ Bharat Thyagarajan $^{6}$, Leslie A. Lange ${ }^{7}$, Eric A. Boerwinkle ${ }^{8}$, David R. Jacobs Jr. ${ }^{9}$, and \\ Myron D. Gross 6 \\ ${ }^{1}$ Division of Epidemiology, Department of Health Sciences Research, Mayo Clinic, Rochester, MN \\ (bielinski.suzette@mayo.edu) \\ 2Department of Epidemiology, University of Washington, Seattle, WA \\ (apreiner@u.washington.edu) \\ ${ }^{3}$ Department of Genome Sciences, University of Washington, Seattle, WA \\ (debnick@u.washington.edu) \\ ${ }^{4}$ Division of Public Health Sciences, Fred Hutchinson Cancer Research Center, Seattle, WA \\ (ccarlson@fhcrc.org) \\ ${ }^{5}$ Division of Biostatistics and Informatics, Department of Health Sciences Research, Mayo Clinic, \\ Rochester, MN (bailey.kent@mayo.edu) \\ ${ }^{6}$ Department of Laboratory Medicine and Pathology, University of Minnesota, Minneapolis, MN \\ (thya0003@umn.edu \& gross001@umn.edu)) \\ ${ }^{7}$ Department of Genetics, University of North Carolina, Chapel Hill, NC \\ (leslie_lange@med.unc.edu) \\ ${ }^{8}$ Human Genetics Center and Institute of Molecular Medicine, University of Texas Health Science \\ Center, Houston, TX (eric.boerwinkle@uth.tmc.edu) \\ ${ }^{9}$ Division of Epidemiology \& Community Health, School of Public Health, University of Minnesota, \\ Minneapolis, MN; also affiliated with Department of Nutrition, University of Oslo, Oslo, Norway \\ (jacob004@umn.edu)
}

\section{Abstract}

Objective-Polymorphisms within the ICAM1 structural gene have been shown to influence circulating levels of soluble intercellular adhesion molecule -1 (sICAM-1) but their relation to atherosclerosis has not been clearly established. We sought to determine whether ICAM1 SNPs are associated with circulating sICAM-1 concentration, coronary artery calcium (CAC), and common and internal carotid intima medial thickness (IMT).

\footnotetext{
(C) 2011 Elsevier Ireland Ltd. All rights reserved.

Corresponding Author: Suzette J. Bielinski, PhD; Assistant Professor of Epidemiology; Mayo Clinic College of Medicine; Harwick Building 6-56; 200 1st Street SW; Rochester, Minnesota 55905; Office: 507-538-4914; Fax: 507-284-1516; bielinski.suzette@mayo.edu.

Conflict of Interest/Disclosures

None

Publisher's Disclaimer: This is a PDF file of an unedited manuscript that has been accepted for publication. As a service to our customers we are providing this early version of the manuscript. The manuscript will undergo copyediting, typesetting, and review of the resulting proof before it is published in its final citable form. Please note that during the production process errors may be discovered which could affect the content, and all legal disclaimers that apply to the journal pertain.
} 
Methods and Results-3,550 black and white Coronary Artery Risk Development in Young Adults (CARDIA) Study subjects who participated in the year 15 and/or 20 examinations and were part of the Young Adult Longitudinal Study of Antioxidants (YALTA) ancillary study were included in this analysis. In whites, rs5498 was significantly associated with sICAM-1 ( $\mathrm{p}<0.001)$ and each G-allele of rs5498 was associated with 5\% higher sICAM-1 concentration. In blacks, each C-allele of rs5490 was associated with $6 \%$ higher sICAM-1 level; this SNP was in strong linkage disequilibrium with rs5491, a functional variant. Subclinical measurements of atherosclerosis in either year 15 or year 20 were not significantly related to ICAM1 SNPs.

Conclusions-In CARDIA, ICAM1 DNA segment variants were associated with sICAM-1 protein level including the novel finding that levels differ by the functional variant rs5491. However, ICAM1 SNPs were not strongly related to either IMT or CAC. Our findings in CARDIA suggest that ICAM1 variants are not major early contributors to subclinical atherosclerosis.

\section{Keywords}

cell adhesion molecules; atherosclerosis; coronary calcium; genetics; inflammation

\section{Introduction}

Atherogenesis is a chronic inflammatory process. Steps in the inflammatory process include accumulation of lipids, recruitment of leukocytes and smooth muscle cells into vessel walls, and accumulation of extracellular matrix. Intercellular adhesion molecule-1 (ICAM-1) is integral in these cellular processes as interactions between ICAM-1 and activated receptors on the leukocytes result in firm adhesion and transmigration of leukocytes into the basement membrane of the vasculature. Therefore, ICAM-1 may be an important contributor to the development and progression of atherosclerotic disease.

Nakashima et al. showed upregulation of ICAM1 at atherosclerosis-prone sites, and animal studies have shown a reduction in atherosclerosis in mice deficient in ICAM-1 ${ }^{1-4}$.

Circulating soluble ICAM-1 (sICAM-1) is thought to be the result of cleavage of membranebound ICAM-1 and its concentration in serum/plasma has an estimated heritability ranging from $0.34-0.50^{5,6}$. Several human studies have found high levels of inflammatory-related markers in patients with cardiovascular disease ${ }^{7-10}$. The ARIC study reported the odds of coronary heart disease and carotid artery atherosclerosis were 5.5 and 2.6 times higher respectively, for those with levels of sICAM-1 in the highest quartile compared with those in the lowest quartile ${ }^{10}$. The Women's Health Study reported a relative risk of 2.6 for cardiovascular events for women in the highest quartile of sICAM-1 levels compared to lowest ${ }^{11}$.

Results from three genome-wide linkage scans of sICAM-1 showed significant linkage on chromosome 19 near the ICAM1 structural gene ${ }^{6,12,13}$. Polymorphisms within the ICAM1 structural gene have been shown to influence circulating levels of sICAM-1 but the relation of these polymorphisms and atherosclerosis remains inconclusive ${ }^{14,15}$. Furthermore, the relationship of ICAM1 SNPs on sICAM-1 levels and atherosclerosis in younger populations is unknown. Therefore, we sought to determine whether variations within the ICAM1 gene are associated circulating sICAM- 1 concentrations and subclinical atherosclerosis in a cohort of young adults. 


\section{Methods}

\section{Subjects}

This cross-sectional study was part of the Young Adult Longitudinal Study of Antioxidants (YALTA), an ancillary study to the Coronary Artery Risk Development in Young Adults (CARDIA) study, a cohort study, which tracks the evolution of cardiovascular disease risk factors in human subjects beginning at ages 18-30 in 1985-86. CARDIA recruited a population based sample of 5,115 black and white men and women in Birmingham, AL, Chicago, IL, Minneapolis, MN, and Oakland, CA with participants reexamined at years 2, 5, $7,10,15$, and 20. Overall retention rates for follow-up examinations among surviving participants were: $91 \%$ at year 2, 86\% at year $5,81 \%$ at year $7,79 \%$ at year $10,74 \%$ at year 15 , and $71 \%$ at year 20 . Further details of the study have been described elsewhere ${ }^{16}$. This analysis was based on subjects who participated in the year 15 examination that occurred between May 2000 and June 2001 and who had available fasting plasma samples and consented to the use of their DNA. Analysis involving subclinical atherosclerosis measures required participation in the year 20 examination as IMT was only measured at the year 20 exam.

\section{Measurements}

Demographic, and lifestyle information were collected via questionnaire, and measurements were taken of height and weight to calculate body mass index $\left(\mathrm{BMI}, \mathrm{kg} / \mathrm{m}^{2}\right)$. Resting systolic and diastolic blood pressure was measured using the averages of the second and third random zero sphygmomanometer measurements.

Overnight fasting blood samples were collected and processed within 90 minutes of blood collection and stored at $-70^{\circ} \mathrm{C}$. Soluble ICAM- 1 concentrations were measured in serum (R\&D Systems; Cat No DY720). The limit of sensitivity of the ICAM-1 assay was $15 \mathrm{pg}$ / $\mathrm{mL}$ and the coefficient of variation was $9.4 \%$. The correlation of 287 pairs of blinded quality control samples was 0.884 . Plasma total cholesterol, HDL-cholesterol, and triglycerides were measured enzymatically at the Northwest Lipid Research Laboratory at the University of Washington, Seattle, WA. High-density lipoprotein cholesterol (HDL-C) was determined after precipitation of low-density lipoprotein (LDL)-containing lipoproteins with dextran sulfate/magnesium chloride. LDL-cholesterol (LDL-C) was calculated using the Friedewald equation; the few individuals with triglycerides over $4.52 \mathrm{mmol} / \mathrm{liter}(400 \mathrm{mg} / \mathrm{dL})$ were excluded from this calculation. The test-retest correlation, in 448 blind duplicate samples, was 0.98-0.99 for total cholesterol, HDL-C, LDL-C, and triglycerides.

Coronary artery calcium (CAC) was measured in years 15 and 20 in Oakland, CA and Chicago, IL by electron beam CT (Imatron, Inc.) and in Birmingham, AL and Minneapolis, MN by multidetector CT (General Electric Lightspeed in Birmingham and Siemens S4+ Volume Zoom in Minneapolis). Pregnant women and those subjects who exceeded the weight restriction for the scanner were ineligible. The CT scanning protocol included a hydroxyl-apatite phantom to monitor image brightness and noise, and adjustment of scanner differences in brightness levels during reading and to allow comparability of scans among sites. A radiologist identified the courses of the coronary arteries using specially developed image processing software programmed to define a calcified focus as 4 adjacent pixels comprising an area of at least $1.87 \mathrm{~mm}^{2}$. Agatston scores calculated for each artery (left main, left anterior descending, left circumflex, and right coronary artery) were summed across all arteries to obtain the total calcium score used in all analyses. Scans were done in duplicate; scan pairs were adjudicated side-by-side by a radiologist and in those judged falsely positive the Agatston score was reset to zero. 
Carotid ultrasound was performed at the year 20 CARDIA using a standard protocol. The maximum intima-media thicknesses (IMT) of the common carotid artery and the bulb/ internal carotid artery were defined as the mean of the maximal IMT of the near and far wall on both the left and right sides.

Haplotype tagging SNPs in the ICAM1 structural gene were selected based on a $\mathrm{R}^{2}$ cut-off of 0.8 and a minor allele frequency greater than 0.05. The hapolotype tagging SNPs were selected separately for African Americans and European Americans. Genotyping was carried out with a combination of mass spectrometry based on multiplex methods (Sequenom, San Diego, CA) and TaqMan (Applied Biosystems, Foster City, CA) assays. Those SNPs failing design or quality control in the multiplex methods were moved to the TaqMan assay. Primers and probes for the genotyping assays are available from the authors upon request.

\section{Statistical Analysis}

Hardy Weinberg equilibrium (HWE) was assessed using the log likelihood ratio test stratified by race for all SNPs. Haploview was used to determine linkage disequilibrium. Associations between genotype and sICAM-1 were assessed with linear regression. In CARDIA, roughly $80 \%$ of the participants at both exams had a CAC score of zero and the remaining non-zero scores were highly skewed. Therefore, we modeled CAC in two ways, as a continuous trait, $\log$ (Agatston Score +1 ), and as a dichotomous trait (presence or absence of CAC). All associations were stratified by race/ethnicity to reduce confounding due to population stratification and to evaluate heterogeneity in the associations. We used logistic regression to assess the association between genotype and the presence of CAC. Generalized linear models (GENMOD) were used to determine the association between genotype and continuous CAC and IMT measures. SNP genotypes were analyzed for predicting association under an additive model relating the number of minor alleles $(0,1,2)$ to phenotype. Only SNPs with $>1 \%$ allele frequency in each racial group were included in the analysis. To correct for multiple comparisons, we used a Bonferroni correction based on the total number of race-SNP tests, giving us a threshold of $p<0.002(0.05 / 22)$.

The associations of ICAM1 SNPs, sICAM-1, CAC, and IMT were assessed with and without covariates. Covariates included age, sex, center, smoking status, alcohol consumption, HDL cholesterol, LDL cholesterol, triglycerides, and fasting insulin, and glucose measured at exam 15. In blacks only, an ancestry estimate was included as a covariate. We report the most parsimonious model that includes only genotype as the addition of covariates did not materially change any of the associations.

\section{Results}

Study characteristics by race are listed in Table 1 . Blacks were slightly younger and more likely female, had significantly thicker IMT at both sites (internal, $p=0.003$ and common, $p$ $<0.001)$ and higher levels of sICAM-1 ( $<<0.0001)$. Conversely, whites had significantly more coronary calcium on average in year $15(\mathrm{p}<0.001)$ and year $20(\mathrm{p}<0.002)$. ICAM1 SNP allele frequencies by race are listed in Online Table 1 with descriptions of the SNPs including amino acid substitution and location. With two exceptions in blacks only, rs281431 and rs281434, all ICAM1 SNPs were in HWE (p > 0.05). For SNP rs281434 there were fewer heterozygotes than expected $(\mathrm{p}=0.005)$ and for $\mathrm{rs} 281431$ there were more heterozygotes than expected $(\mathrm{p}=0.04)$ (Online Table 2). Online Figures 1 and 2 illustrate the linkage disequilibrium plots generated by Haploview for each race. Online Figures $3 \& 4$ illustrates SNP associations across the ICAMI gene for each racial group. 
Geometric means of sICAM- 1 concentration by genotype are listed in Table 2 for all ICAM1 SNPs. In whites, rs5498 and rs3093030 were significantly associated with sICAM-1 ( $\mathrm{p}<0.001$ ). SNP rs5498 encodes a non-synonymous substitution in exon 6, whereas rs3093030 is located in the 5' region. These two SNPs are in strong LD in whites, $\mathrm{r}^{2}=0.93$. To further investigate this association we performed an analysis on the rs3093030 and sICAM-1 relationship conditioning on rs5498 genotype (i.e. including rs5498 in the model as a covariate). The association remained significant, at the $\mathrm{p}=0.05$ level, for $\mathrm{rs} 5498$ ( $\mathrm{p}=$ 0.01 ) but not for $r s 3093030(\mathrm{p}=0.15)$. Each G-allele of rs5498 was associated with 5\% higher sICAM-1 level per allele. Six other SNPs were associated at the $p=0.05$ level and are in LD with rs5498 ( $\mathrm{r}^{2}$ ranges 0.04-0.30); rs5030390 ( $\left.\mathrm{p}=0.04\right)$, rs $281430(\mathrm{p}=0.03)$, rs281431 ( $\mathrm{p}=0.02), r s 281434(\mathrm{p}=0.02), r s 281437(\mathrm{p}=0.03)$, and rs3093032 ( $\mathrm{p}=0.03)$. However, after conditioning on rs5498, none of those six SNPs were related to sICAM-1 level ( $p>0.19$ ) while rs5498 remained significant ( $p<0.0001)$. In blacks, rs5498 was not associated with sICAM-1 level $(\mathrm{p}=0.72)$.

In blacks, rs5490 was significantly associated with sICAM-1 level ( $\mathrm{p}<0.0008)$. Each Callele was associated with $6 \%$ higher sICAM-1 level. ICAM1 SNPs rs281430 $(\mathrm{p}=0.01)$, rs281431 ( $\mathrm{p}=0.04), \operatorname{rs} 281432(\mathrm{p}=0.04)$, and $\mathrm{rs} 281437(\mathrm{p}=0.01)$ were all modestly associated with sICAM-1 level and in LD with rs5490 ( $\mathrm{r}^{2}$ ranges $\left.0.01-0.15\right)$. After conditioning on rs 5490, only rs 281437 remained modestly associated with sICAM-1 ( $\mathrm{p}=$ $0.04)$ while the other four SNPs were unrelated ( $p>0.23$ ) and rs5490 remained a strong predictor $(\mathrm{p}=0.0004)$. We did not assess these relationships in whites as this SNP is rare, frequency $<1 \%$.

For the year $15 \mathrm{CAC}$ measurement, there were no ICAM1 SNPs associated with CAC in either racial group (Online Tables $3 \& 4$ ). For year 20, there were no ICAM1 SNPs significantly $(\mathrm{p}>0.002)$ related to either CAC or IMT. However, several SNP were associated with subclinical disease at the $\mathrm{p}=0.05$ level. In blacks, SNPs rs3093030, rs281434, rs5498, rs5030362, and rs5490 were all associated with common carotid IMT (p range 0.02-0.05). In addition to common carotid IMT, rs5490 was also associated with presence of $\mathrm{CAC}(\mathrm{OR}=1.4$ per $\mathrm{C}$-allele, $\mathrm{p}=0.02)$ but not continuous $\mathrm{CAC}(\mathrm{p}=0.23)$ in year 20. In whites, only rs281437 was marginally related to internal IMT $(p=0.04)$

\section{Discussion}

This study sought to determine the relationship of variants within the ICAM1 structural gene, circulating sICAM-1, and subclinical atherosclerosis in a cohort of young adults. This study shows that ICAM1 SNPs are associated with sICAM-1 levels in a relatively young healthy population, replicating the results from cohorts of older subjects and demonstrating genetic influences of levels of this risk factor at the earliest stages of atherosclerosis. Specifically, each minor allele of rs5498 was associated with a 5\% higher sICAM-1 level in whites and the minor allele of rs5490 was associated with a 6\% higher sICAM-1 levels in blacks. No strong associations of these variants with IMT or CAC were observed.

ICAM1 SNP rs5498 is a functional mutation located at the C-terminus encoding a glutamic acid - lysine substitution in exon six and as stated above is in strong LD with intronic SNP rs3093030. Consistent with our results in whites, this SNP has been previously associated with sICAM-1 level in a German pediatric asthma population ${ }^{17}$ and whites in the Multiethnic Study of Atherosclerosis (MESA) with no association observed in blacks ${ }^{14}$. This result corroborates findings from a genome wide association study in whites of sICAM-1 in the Women's Genome Health Study that identified three ICAM1 SNPs, rs1799969, rs5498, and rs281437, that were significantly related with sICAM-1 at a genome-wide significance level ${ }^{18}$. Further replication of this association was reported $\sim 10,000$ individuals of European 
Ancestry in the Cohorts for Heart and Aging Research in Genome Epidemiology (CHARGE) Consortium ${ }^{13}$.

SNP rs5498 is located 3 base pairs upstream of a splice donor site that produces an alternatively spliced form of ICAM-1 that lacks a transmembrane and intracellular domain (ICAM-1-S). Using human peripheral mononuclear cells and Epstein-Barr virus transformed peripheral mononuclear cells, Iwao et al demonstrated that carriers of the G-allele may have more difficulty splicing ICAM-1-S compared to the A-allele resulting in GG cells having less mRNA for ICAM-1-S $\mathrm{S}^{19}$. Therefore, one hypothesis given these results is that due to disruption of the splice site, carriers of the G-allele produce less ICAM-1-S and more ICAM-1-L that contains both transmembrane and cellular domains. Given that SICAM-1 is thought to be produced by cleavage of membrane bound ICAM- $1^{20}$, individuals who produce more ICAM-1-L would likely have higher levels of sICAM-1. Differing linkage disequilibrium patterns between ethnic groups for rs5498 and splice site mutations may account for the lack of replication for rs5498 on sICAM-1 levels in blacks. However, in contrast to previous studies, including the CARDIA results reported here, Iwao et al reported that total sICAM-1 was similar for both homozygote samples but 50\% lower in the heterozygote cells ${ }^{19}$. Interactions between ICAM1 SNPs and ELISA ICAM-1 assays are well-documented in the literature 21,22 . However, it is unknown as to whether assay affinity differences by genotype account for this discrepancy.

SNP rs5490 is located in the 5'UTR and was associated with sICAM-1 in blacks. Based on data from HapMap African samples this SNP is in strong LD with rs5491 $\left(\mathrm{r}^{2}=0.78\right)$, a functional variant, with the rs5490 C-allele and the rs5491 T-allele commonly residing on the same haplotype. It has been hypothesized that the T-allele of rs5491 confers protection against malarial infection ${ }^{23}$; hence the allele is common in African populations with a frequency of 0.25 in Yoruban and monomorphic in Europeans based on HapMap data. The T-allele of rs5491 encodes a lysine to methionine substitution in exon 2 in the $\mathrm{N}$-terminal domain of ICAM-1 and results in a protein that is unable to bind to fibrinogen and has a decreased affinity for T-cells at lower ICAM-1 concentrations compared to wild type ICAM- $1^{23}$. A commonly used R\&D Systems sICAM-1 assay is unable to recognize sICAM-1 ${ }^{\text {rs5491T }}$ making the assessment of rs5491 on sICAM-1 concentrations impossible in studies using the problematic assay ${ }^{21}$. In CARDIA, an alternative assay was used that is not affected by this variant and for the first time we are able to show that sICAM-1 protein concentrations differ by rs5491 genotype. However, given the lack of knowledge regarding the functionality of rs5490 and the lack of genotype data for rs5491 in CARDIA, we are unable to determine if the observed association with sICAM-1 is caused by rs5490, rs5491, or another functional variant in LD.

ICAM1 SNP rs281437 is modestly associated with sICAM-1 in blacks after conditioning on rs5490. This SNP is located in the 3' UTR and was identified in a recent genome wide association study of sICAM-1 in whites ${ }^{18}$. Other relationships for rs 281437 are absent from the literature, because this SNP has not been genotyped in other populations.

Several reasons could explain the heterogeneity of associations by race seen in previous studies and corroborated by this investigation. Possible mechanisms causing the racial heterogeneity may include genotype frequency differences affecting the power to detect associations, differing LD patterns between racial groups, and evidence of selection pressure at this locus where malaria is endemic ${ }^{23}$. As with any candidate gene study, LD patterns make it difficult to positively identify the causal variant.

In CARDIA, ICAM1 SNPs were not significantly associated with subclinical atherosclerosis but the power to detect an association was limited in this cohort; especially considering that 
genetic association results of most complex biological traits has shown us that the effect size of a single variant is small. The best case in terms of power for our data is for the SNP with the highest minor allele frequency in each racial group and the presence of CAC at year 20. For this case, we have $80 \%$ power to detect an OR of 1.5 in blacks for rs 281437 and 1.4 in whites for rs5498. Power is reduced for all other SNP-subclinical measurement combinations. Considering these same two SNP-race combinations, we have $80 \%$ power to detect an OR of 1.8 in blacks and 1.6 in whites for CAC at year 15 and differences in IMT ranging from 0.02-0.04 mm. Thus, identification of SNPs with minor effects is challenging in this cohort. However, despite our limited power, several SNPs were modestly associated with subclinical disease including rs3093030, rs281434, rs5498, rs5030362, and rs5490 in blacks and rs281437 in whites. Several previous studies have found an association with ICAM1 SNPs and cardiovascular disease, albeit inconsistently. In a German case control study, rs5498 was associated with an OR $=2.2$ for coronary heart disease ${ }^{24}$, in the Study of Inherited Risk of Coronary Atherosclerosis (SIRCA) this SNP was associated with CAC in men independently of sICAM-1 level ${ }^{25}$, and was associated with a higher risk of restenosis after coronary stenting in Chinese ${ }^{26}$. The rs5498 SNP was also associated with peripheral arterial occlusive disease in an Italian population ${ }^{27}$. Conversely, ICAM1 variants were not associated with ischemic heart disease ${ }^{28}$, coronary heart disease ${ }^{29}$, myocardial infarction $^{29,30}$, or incident cardiovascular disease ${ }^{31}$. Furthermore, ICAM1 variants were not associated with CAC in the MESA Study ${ }^{14}$.

This investigation has several strengths. CARDIA is a large population-based study with ample sample size in two racial groups to investigate the relationship between ICAM1 SNPs and sICAM-1. Furthermore, CARDIA is unique in that the subjects were recruited at a relatively young age allowing for the evaluation of risk factors at the earliest stages of atherosclerosis.

\title{
Conclusion
}

In CARDIA, ICAM1 variants associated with sICAM-1 protein levels but were not strongly related to either IMT or CAC. Our findings in CARDIA suggest that ICAM1 variants are not major early contributors to subclinical atherosclerosis.

\section{Supplementary Material}

Refer to Web version on PubMed Central for supplementary material.

\section{Acknowledgments}

\author{
Support \\ Supported by the National Heart, Lung, and Blood Institute of the United States (YALTA: NIH 1RO1-HL53560 \\ and CARDIA: NO1-HC-48047 through 48050, HL072810).
}

\section{References}

1. Nakashima Y, Raines EW, Plump AS, Breslow JL, Ross R. Upregulation of VCAM-1 and ICAM-1 at atherosclerosis-prone sites on the endothelium in the ApoE-deficient mouse. Arterioscler Thromb Vasc Biol. 1998; 18:842-851. [PubMed: 9598845]

2. Peters W, Charo IF. Involvement of chemokine receptor 2 and its ligand, monocyte chemoattractant protein-1, in the development of atherosclerosis: lessons from knockout mice. Curr Opin Lipidol. 2001; 12:175-180. [PubMed: 11264989] 
3. Gu L, Okada Y, Clinton SK, Gerard C, Sukhova GK, Libby P, Rollins BJ. Absence of monocyte chemoattractant protein-1 reduces atherosclerosis in low density lipoprotein receptor-deficient mice. Mol Cell. 1998; 2:275-281. [PubMed: 9734366]

4. Collins RG, Velji R, Guevara NV, Hicks MJ, Chan L, Beaudet AL. P-Selectin or intercellular adhesion molecule (ICAM)-1 deficiency substantially protects against atherosclerosis in apolipoprotein E-deficient mice. J Exp Med. 2000; 191:189-194. [PubMed: 10620617]

5. Dupuis J, Larson MG, Vasan RS, Massaro JM, Wilson PW, Lipinska I, Corey D, Vita JA, Keaney JF Jr, Benjamin EJ. Genome scan of systemic biomarkers of vascular inflammation in the Framingham Heart Study: evidence for susceptibility loci on 1q. Atherosclerosis. 2005; 182:307314. [PubMed: 16159603]

6. Kent JW Jr, Mahaney MC, Comuzzie AG, Goring HH, Almasy L, Dyer TD, Cole SA, Maccluer JW, Blangero J. Quantitative trait locus on Chromosome 19 for circulating levels of intercellular adhesion molecule-1 in Mexican Americans. Atherosclerosis. 2006

7. Lee WH, Lee Y, Kim JR, Chu JA, Lee SY, Jung JO, Kim JS, Kim S, Seo JD, Rhee SS, Park JE. Activation of monocytes, T-lymphocytes and plasma inflammatory markers in angina patients. Exp Mol Med. 1999; 31:159-164. [PubMed: 10551265]

8. Ridker PM, Hennekens CH, Roitman-Johnson B, Stampfer MJ, Allen J. Plasma concentration of soluble intercellular adhesion molecule 1 and risks of future myocardial infarction in apparently healthy men. Lancet. 1998; 351:88-92. [PubMed: 9439492]

9. Signorelli SS, Mazzarino MC, Di Pino L, Malaponte G, Porto C, Pennisi G, Marchese G, Costa MP, Digrandi D, Celotta G, Virgilio V. High circulating levels of cytokines (IL-6 and TNFalpha), adhesion molecules (VCAM-1 and ICAM-1) and selectins in patients with peripheral arterial disease at rest and after a treadmill test. Vasc Med. 2003; 8:15-19. [PubMed: 12866607]

10. Hwang SJ, Ballantyne CM, Sharrett AR, Smith LC, Davis CE, Gotto AM Jr, Boerwinkle E. Circulating adhesion molecules VCAM-1, ICAM-1, and E-selectin in carotid atherosclerosis and incident coronary heart disease cases: the Atherosclerosis Risk In Communities (ARIC) study. Circulation. 1997; 96:4219-4225. [PubMed: 9416885]

11. Ridker PM, Hennekens CH, Buring JE, Rifai N. C-reactive protein and other markers of inflammation in the prediction of cardiovascular disease in women. N Engl J Med. 2000; 342:836843. [PubMed: 10733371]

12. Bielinski SJ, Pankow JS, Foster CL, Miller MB, Hopkins PN, Eckfeldt JH, Hixson J, Liu Y, Register T, Myers RH, Arnett DK. Circulating soluble ICAM-1 levels shows linkage to ICAM gene cluster region on chromosome 19: the NHLBI Family Heart Study follow-up examination. Atherosclerosis. 2008; 199:172-178. [PubMed: 18045607]

13. Barbalic M, Dupuis J, Dehghan A, Bis JC, Hoogeveen RC, Schnabel RB, Nambi V, Bretler M, Smith NL, Peters A, Lu C, Tracy RP, Aleksic N, Heeriga J, Keaney JF Jr, Rice K, Lip GY, Vasan RS, Glazer NL, Larson MG, Uitterlinden AG, Yamamoto J, Durda P, Haritunians T, Psaty BM, Boerwinkle E, Hofman A, Koenig W, Jenny NS, Witteman JC, Ballantyne C, Benjamin EJ. Largescale genomic studies reveal central role of ABO in sP-selectin and sICAM-1 levels. Hum Mol Genet. 19:1863-1872. [PubMed: 20167578]

14. Bielinski SJ, Pankow JS, Li N, Hsu FC, Adar SD, Jenny NS, Bowden DW, Wasserman BA, Arnett D. ICAM1 and VCAM1 polymorphisms, coronary artery calcium, and circulating levels of soluble ICAM-1: The multi-ethnic study of atherosclerosis (MESA). Atherosclerosis. 2008

15. Tang W, Pankow JS, Carr JJ, Tracy RP, Bielinski SJ, North KE, Hopkins PN, Kraja AT, Arnett DK. Association of sICAM-1 and MCP-1 with coronary artery calcification in families enriched for coronary heart disease or hypertension: the NHLBI Family Heart Study. BMC Cardiovasc Disord. 2007; 7:30. [PubMed: 17963506]

16. Friedman GD, Cutter GR, Donahue RP, Hughes GH, Hulley SB, Jacobs DR Jr, Liu K, Savage PJ. CARDIA: study design, recruitment, and some characteristics of the examined subjects. J Clin Epidemiol. 1988; 41:1105-1116. [PubMed: 3204420]

17. Puthothu B, Krueger M, Bernhardt M, Heinzmann A. ICAM1 amino-acid variant K469E is associated with paediatric bronchial asthma and elevated sICAM1 levels. Genes Immun. 2006; 7:322-326. [PubMed: 16625213] 
18. Pare G, Chasman DI, Kellogg M, Zee RY, Rifai N, Badola S, Miletich JP, Ridker PM. Novel association of ABO histo-blood group antigen with soluble ICAM-1: results of a genome-wide association study of 6,578 women. PLoS Genet. 2008; 4:e1000118. [PubMed: 18604267]

19. Iwao M, Morisaki H, Morisaki T. Single-nucleotide polymorphism g.1548G > A (E469K) in human ICAM-1 gene affects mRNA splicing pattern and TPA-induced apoptosis. Biochemical and biophysical research communications. 2004; 317:729-735. [PubMed: 15081401]

20. Champagne B, Tremblay P, Cantin A, St Pierre Y. Proteolytic cleavage of ICAM-1 by human neutrophil elastase. J Immunol. 1998; 161:6398-6405. [PubMed: 9834131]

21. Register TC, Burdon KP, Lenchik L, Bowden DW, Hawkins GA, Nicklas BJ, Lohman K, Hsu FC, Langefeld CD, Carr JJ. Variability of serum soluble intercellular adhesion molecule-1 measurements attributable to a common polymorphism. Clin Chem. 2004; 50:2185-2187. [PubMed: 15502096]

22. Bielinski SJ, Pankow JS, Li N, Hsu FC, Adar SD, Jenny NS, Bowden DW, Wasserman BA, Arnett D. ICAM1 and VCAM1 polymorphisms, coronary artery calcium, and circulating levels of soluble ICAM-1: the multi-ethnic study of atherosclerosis (MESA). Atherosclerosis. 2008; 201:339-344. [PubMed: 18420209]

23. Craig A, Fernandez-Reyes D, Mesri M, McDowall A, Altieri DC, Hogg N, Newbold C. A functional analysis of a natural variant of intercellular adhesion molecule-1 (ICAM-1Kilifi). Hum Mol Genet. 2000; 9:525-530. [PubMed: 10699175]

24. Jiang H, Klein RM, Niederacher D, Du M, Marx R, Horlitz M, Boerrigter G, Lapp H, Scheffold T, Krakau I, Gulker H. C/T polymorphism of the intercellular adhesion molecule-1 gene (exon 6, codon 469). A risk factor for coronary heart disease and myocardial infarction. International journal of cardiology. 2002; 84:171-177. [PubMed: 12127369]

25. Reilly MP, Wolfe ML, Dykhouse J, Reddy K, Localio AR, Rader DJ. Intercellular adhesion molecule 1 (ICAM-1) gene variant is associated with coronary artery calcification independent of soluble ICAM-1 levels. J Investig Med. 2004; 52:515-522.

26. Liu ZP, Huo Y, Li JP, Zhang Y, Xue L, Zhao CY, Hong XM, Huang AQ, Gao W. Polymorphism $\mathrm{K} 469 \mathrm{E}$ of intercellular adhesion molecule-1 gene and restenosis after coronary stenting in Chinese patients. Chin Med J (Engl). 2004; 117:172-175. [PubMed: 14975197]

27. Gaetani E, Flex A, Pola R, Papaleo P, De Martini D, Pola E, Aloi F, Flore R, Serricchio M, Gasbarrini A, Pola P. The K469E polymorphism of the ICAM-1 gene is a risk factor for peripheral arterial occlusive disease. Blood Coagul Fibrinolysis. 2002; 13:483-488. [PubMed: 12192299]

28. McGlinchey PG, Spence MS, Patterson CC, Allen AR, Murphy G, Belton C, McKeown PP. The intercellular adhesion molecule-1 (ICAM-1) gene K469E polymorphism is not associated with ischaemic heart disease: an investigation using family-based tests of association. Eur $\mathbf{J}$ Immunogenet. 2004; 31:201-206. [PubMed: 15379751]

29. Aminian B, Abdi Ardekani AR, Arandi N. ICAM-1 polymorphisms (G241R, K469E), in coronary artery disease and myocardial infarction. Iran J Immunol. 2007; 4:227-235. [PubMed: 18057581]

30. Milutinovic A, Petrovic D. The K469E polymorphism of the intracellular adhesion molecule 1 (ICAM-1) gene is not associated with myocardial infarction in Caucasians with type 2 diabetes. Folia Biol (Praha). 2006; 52:79-80. [PubMed: 17089918]

31. Zee RY, Cheng S, Erlich HA, Lindpaintner K, Rifai N, Buring JE, Ridker PM. Intercellular adhesion molecule 1 (ICAM1) Lys56Met and Gly241Arg gene variants, plasma-soluble ICAM1 concentrations, and risk of incident cardiovascular events in 23,014 initially healthy white women. Stroke. 2007; 38:3152-3157. [PubMed: 17962597] 
Table 1

Characteristics by race (mean $\pm \mathrm{SD}$, percentage, or count)

\begin{tabular}{|c|c|c|c|}
\hline Variables & Black $(n=1652)$ & White $(n=1898)$ & p-value \\
\hline Year 15 Age, years & $40 \pm 3.8$ & $41 \pm 3.4$ & $<0.001$ \\
\hline Male, $\%$ & $681(41)$ & $893(47)$ & 0.005 \\
\hline Internal Carotid IMT, mm & $0.95 \pm 0.22$ & $0.92 \pm 0.22$ & 0.003 \\
\hline range, $\mathrm{mm}$ & $0.44-2.64$ & $0.45-3.0$ & \\
\hline Common Carotid IMT, mm & $0.83 \pm 0.13$ & $0.77 \pm 0.11$ & $<0.001$ \\
\hline range, $\mathrm{mm}$ & $0.53-1.84$ & $0.51-1.35$ & \\
\hline sICAM-1, ng/mL & $166 \pm 50$ & $146 \pm 38$ & $<0.001$ \\
\hline \multicolumn{4}{|l|}{ Year 15 Measurements } \\
\hline CAC Present $(\%)$ & 7.5 & 11.3 & $<0.001$ \\
\hline Range, Agatston Score & $0-2236$ & $0-3521$ & \\
\hline \multicolumn{4}{|c|}{ Agatston Score Categories, n (\%) } \\
\hline$\because 0$ & $1263(92)$ & $1473(89)$ & 0.004 \\
\hline - $1-100$ & $85(6)$ & $158(10)$ & \\
\hline - 101-299 & $11(1)$ & $22(1)$ & \\
\hline - $300+$ & $7(1)$ & $7(<1)$ & \\
\hline \multicolumn{4}{|l|}{ Year 20 Measurements } \\
\hline CAC Present $(\%)$ & 16.1 & 20.5 & 0.004 \\
\hline Range, Agatston Score & $0-6057$ & $0-5350$ & \\
\hline \multicolumn{4}{|c|}{ Agatston Score Categories, n (\%) } \\
\hline - 0 & $1112(84)$ & $1323(80)$ & 0.02 \\
\hline - $1-100$ & $162(12)$ & $259(16)$ & \\
\hline - 101-299 & $37(3)$ & $47(3)$ & \\
\hline - $300+$ & $14(1)$ & $29(2)$ & \\
\hline
\end{tabular}


Table 2

Geometric means for ICAM1 SNP associations with sICAM-1 by race

\begin{tabular}{|c|c|c|c|c|}
\hline \multirow{2}{*}{$\begin{array}{l}\text { ICAMI SNP } \\
\text { blacks }\end{array}$} & \multicolumn{3}{|c|}{ Geometric mean sICAM-1 levels*, ng/mL (n) } & \multirow[t]{2}{*}{ p-value } \\
\hline & & & & \\
\hline rs3093030 (CC,CT,TT) & $161(1186)$ & $161(304)$ & $158(25)$ & 0.64 \\
\hline rs5030390 (GG,GA,AA) & $161(1449)$ & $168(38)$ & n.a. & 0.42 \\
\hline rs281430 (GG,GA,AA) & $165(595)$ & $160(717)$ & $154(212)$ & 0.01 \\
\hline rs281431 (CC,CT,TT) & $166(543)$ & $161(669)$ & $158(161)$ & 0.04 \\
\hline rs281432 (GG,GC,CC) & $164(724)$ & $158(643)$ & $157(152)$ & 0.04 \\
\hline rs281433 (AA,AC,CC) & $160(1298)$ & $166(217)$ & $201(10)$ & 0.06 \\
\hline rs281434 (GG,GA,AA) & $161(713)$ & $161(602)$ & $161(177)$ & 0.95 \\
\hline rs5498 (AA,AG,GG) & $160(963)$ & $163(465)$ & $163(54)$ & 0.72 \\
\hline rs281437 (CC,CT,TT) & $158(648)$ & $161(673)$ & $168(196)$ & 0.01 \\
\hline rs3093032 (CC,CT,TT) & $161(1447)$ & $156(81)$ & $147(4)$ & 0.36 \\
\hline rs5030362 (AA,AC,CC) & $174(15)$ & $167(252)$ & $160(1248)$ & 0.10 \\
\hline rs5490 (AA,AC,CC) & 157 (937) & $168(516)$ & $176(79)$ & 0.0007 \\
\hline \multicolumn{5}{|l|}{ whites } \\
\hline rs3093030 (CC,CT,TT) & $137(548)$ & $145(843)$ & $150(356)$ & $<0.0001$ \\
\hline rs3093035 (GG,GA,AA) & $143(1562)$ & $144(134)$ & n.a. & 0.82 \\
\hline rs5030390 (GG,GA,AA) & $144(1499)$ & $140(244)$ & $127(9)$ & 0.04 \\
\hline rs281430 (GG,GA,AA) & $140(261)$ & $142(901)$ & $146(650)$ & 0.03 \\
\hline rs281431 (CC,CT,TT) & $140(248)$ & $142(863)$ & $146(624)$ & 0.02 \\
\hline rs281432 (GG,GC,CC) & $145(338)$ & $142(902)$ & $144(543)$ & 0.79 \\
\hline rs281434 (GG,GA,AA) & $145(1261)$ & $139(498)$ & $142(51)$ & 0.02 \\
\hline rs5498 (AA,AG,GG) & $137(538)$ & $145(831)$ & $151(350)$ & $<0.0001$ \\
\hline rs281437 (CC,CT,TT) & $145(937)$ & $142(757)$ & $139(128)$ & 0.03 \\
\hline rs3093032 (CC,CT,TT) & $144(1354)$ & $140(428)$ & $136(40)$ & 0.03 \\
\hline
\end{tabular}

* Only SNPs with a frequency of $>1 \%$ were included 